\title{
Hip Replacement: Its Development and Future
}

\author{
Charles Rivière, Ciara Harman, Kartik Logishetty, \\ and Catherine Van Der Straeten
}

\section{Key Points}

- Improvements in implant design and surgical techniques have dramatically reduced the risk of complications, thus reducing the risk of revision surgery while enabling a return to high level of function.

- Complications related to poor components' interaction remain with traditional alignment techniques, despite the more precise implantation of components facilitated by technological assistance.

C. Rivière $(\bowtie)$

The MSK Lab-Imperial College London,

White City Campus, London, UK

South West London Elective Orthopaedic Centre,

Epsom, UK

C. Harman

South West London Elective Orthopaedic Centre,

Epsom, UK

K. Logishetty

The MSK Lab-Imperial College London,

White City Campus, London, UK

e-mail: k.logishetty@imperial.ac.uk

C. Van Der Straeten

Ghent University Hospital,

Corneel Heymanslaan 10, Ghent, Belgium
- Complications related to poor components' interaction are poorly predicted by the radiographic appearance of implant position but have been shown to be correlated with the patient's spinopelvic mobility.

- Personalized strategies for hip arthroplasty taking into account lumbopelvic kinematics and constitutional hip anatomy are under investigation.

- By generating a physiological prosthetic hip (from anatomical restoration of the native) and by optimizing the components interaction during activities of daily living (from selecting a cup orientation that fits the spine flexibility), the kinematic alignment technique for hip replacement may perfect clinical outcomes of prosthetic hip.

\subsection{Evolution of Hip Implant Designs}

There have been significant developments since the first attempts to treat degenerated hips with tissue interpositional arthroplasty (with materials such as fascia lata and pig's bladder) or 
hemi-resurfacing using glass molds by SmithPeterson in 1937 [1]. While the first total hip replacement has been attributed to Wiles in 1938, it was considered a failure-its success and widespread adoption only occurred in the 1960s when Sir John Charnley introduced "lowfriction arthroplasty" using acrylic cement for fixation. This early age of hip arthroplasty has been followed by decades of incremental development directed at reducing failure (including that related to loosening, instability, implant wear, and osteolysis) while accommodating the high-activity profile and increased longevity of the modern patient [1].

Cemented stem designs were progressively refined with distinction between the taper slip and composite beam concepts [2]. Modern techniques for cementing were developed with the use of pulsatile lavage, retrograde femoral canal cement filling, and cement pressurization, but also an appreciation that both the English and French cementing techniques can deliver excellent results [3]. The French technique consists of completely emptying the medullary canal of cancellous bone and implanting a canal-filling femoral component for line-to-line fit, with a thin cement mantle mainly acting as a void filler. This principle - termed the "French paradox"-runs contrary to the perceived wisdom that cement mantles should have a minimal thickness of 2-4 mm and should be complete (English cementation technique). Yet, it is a user-friendly technique that has led to reproducible good long-term clinical outcomes with Charnley-Kerboull and Ceraver Osteal type stems [3].

Uncemented implant designs were developed to solve the issue of osteolysis that was initially but wrongly attributed to cement debris (socalled "cement disease"). Early cementless stem designs were suboptimal because they were excessively stiff (cylindrical shape and chromecobalt alloy) and prone to diaphyseal fixation due to extensive coating. A high rate of mid-thigh pain and proximal bone loss from stress shielding were therefore observed [4]. Subsequent stem designs were designed to be more flexible (noncylindrical shape and titanium-based alloy) and many are partially coated for greater proximal fixation and load transfer [4]. Contemporary

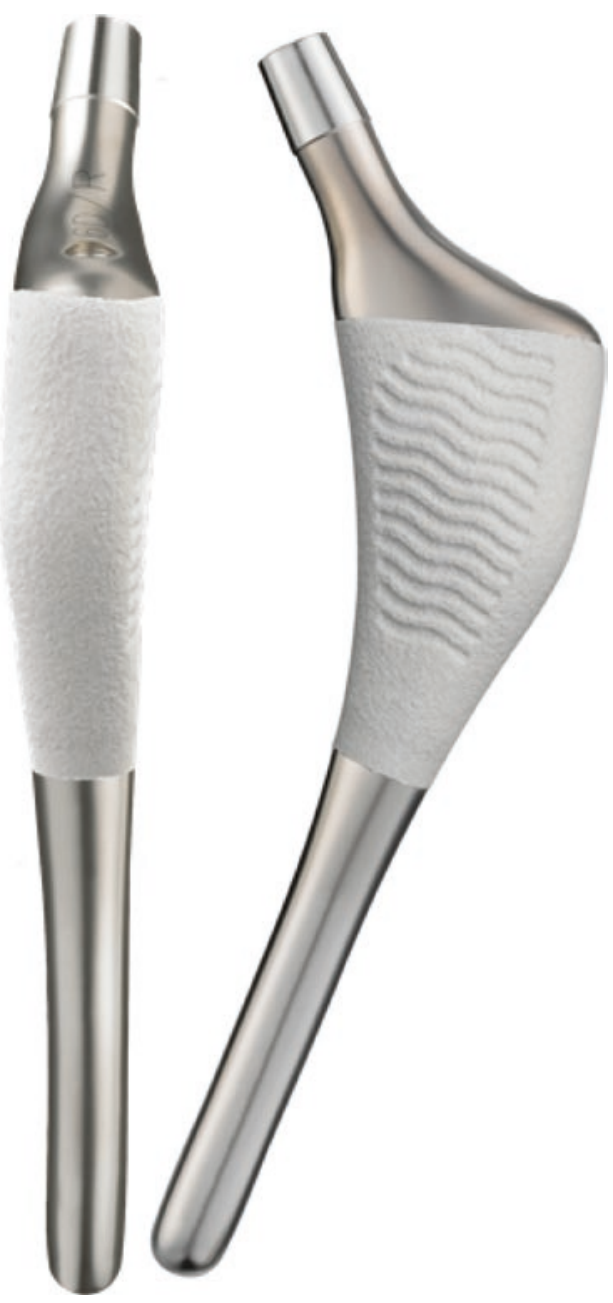

Fig. 3.1 Anatomical femoral stem

uncemented stems are either tapered, cylindrical, or anatomical. This latter group of anatomic design stems closely fill the metaphysis; this promotes physiological load distribution but does not allow intraoperative adjustment of femoral anteversion (Fig. 3.1).

Similar to the evolution of cementless stems, first-generation uncemented cups were poorly designed and had a high rate of failure. A suboptimal locking mechanism design permitted excessive micromotion between the liner and the metal back. This generated a high amount of polyethylene debris and subsequent osteolysis and aseptic loosening [1]. At revision, it was noted that early component designs had a significant amount of fibrous tissue at the bone-implant 
interface. Hydroxyapatite coating was therefore introduced to cementless cups to enhance bone ingrowth and stimulate bony gap closure [5].

In the 1980s, the realization that osteolysis was caused by a host reaction against polyethylene wear particles and not cement debris shifted the focus to reducing bearing surface wear [1]. First-generation ultrahigh molecular weight polyethylene (UHMWPE) had a low abrasive wear resistance and was therefore vulnerable to volumetric wear. The generated debris was responsible for triggering a macrophagic response in periprosthetic tissue, and bone resorption by activated osteoclasts. Low-wear highly crosslinked polyethylene have since been introduced alongside alternative bearings either made of ceramic or metal (cobalt chromium) or, more recently, in Oxinium ${ }^{\mathrm{TM}}$ - a ceramicized metal alloy [1]. After decades of developmentsincluding four generations of ceramic-modern bearing couples of metal-on-highly X-linked polyethylene, ceramic-on-highly X-linked polyethylene, and ceramic-on-ceramic are now recognized as the most reliable options [1, 6, 7].

Increasing the femoral head diameter improves the interaction between the head and cup components by increasing jump distance and stability and reducing the risk of microseparation, edge loading, prosthetic impingement, and dislocation $[8,9]$. This increase in contact surface area is tolerated by modern bearing couples as they are resistant to abrasive wear, while with first-generation UHMWPE abrasive wear was higher with larger diameter femoral heads. When used with total hip implants, recent designs of metal-onmetal large-diameter bearings have been shown to result in high torque and excessive fretting corrosion at the head-neck junction (trunnionosis) with subsequent clinically deleterious adverse reactions to metal debris [1]. When used for hip resurfacing, the same metal-on-metal bearings were demonstrated to be safe in well-designed and well-positioned implants, i.e., avoiding edge loading $[1,6,7]$. In order to prevent the risk of ceramic liner fracture and promote ceramic-onceramic large-diameter bearings for total hip replacement, monoblock ceramic cups with a preassembled ceramic liner housed within a metal back were developed (Fig. 3.2). These have good

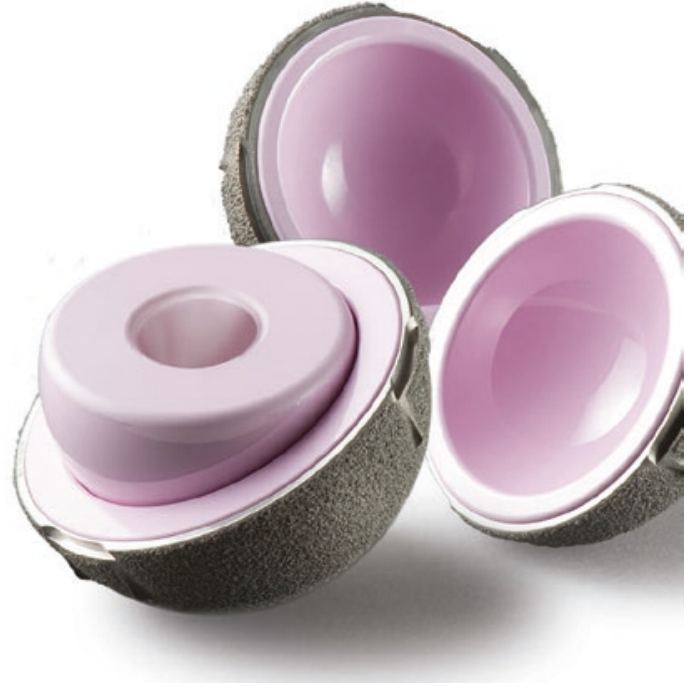

Fig. 3.2 Monoblock ceramic acetabular cup

midterm clinical outcomes despite frequent noise generation (squeaking), which have a negligible clinical impact [10-12].

Another innovation designed to reduce the risk of dislocation is the dual mobility cup design (Fig. 3.3) [13]. Bousquet and Rambert posited that by introducing a mobile articulation between the cup and head, patients could have a higher range of impingement-free movement. Emerging clinical results suggest that dual mobility cups can reduce the incidence of dislocation in primary and revision hip arthroplasty and may be useful in primary total hip arthroplasty in patients with limited spino-pelvic mobility, neuromuscular disease, or soft tissue problems $[14,15]$.

Finally, femoral neck preserving short stem designs (Fig. 3.4) [16], which favor preservation of proximal femur anatomy and bone stock, and minimally invasive surgery have also shown good midterm outcomes since the turn of the century. The expected benefits of more physiological metaphyseal loading, faster recovery, reduced late periprosthetic fracture, easier revision, when compared to conventional stem design, remain to be proven [16].

All of these developments have contributed to the success of hip replacement surgery and its qualification as the "operation of the century" [1]. Return to normal function and satisfaction are generally obtained, with implants survival of $95 \%$ at 14 years reported in the National Joint 


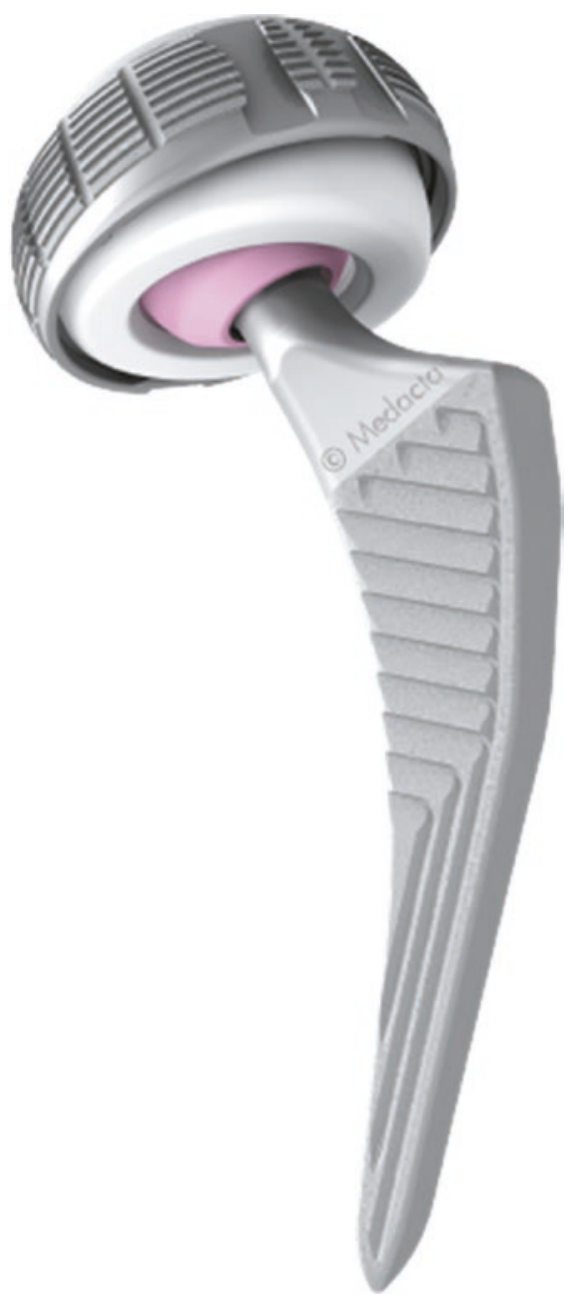

Fig. 3.3 A dual-mobility cup articulating with a ceramic head inserted on a cementless stem

Registry, regardless of the type of fixation and bearing (the exception being for certain large metal on metal bearings) $[6,7]$.

\subsection{Evolution of Instrumentation for Implanting Hip Components}

The precise orientation of implants has traditionally been dependent on a surgeon's visuospatial ability, with the help of basic instruments like alignment rods. Technological assistance could enable surgeons to increase reproduc-
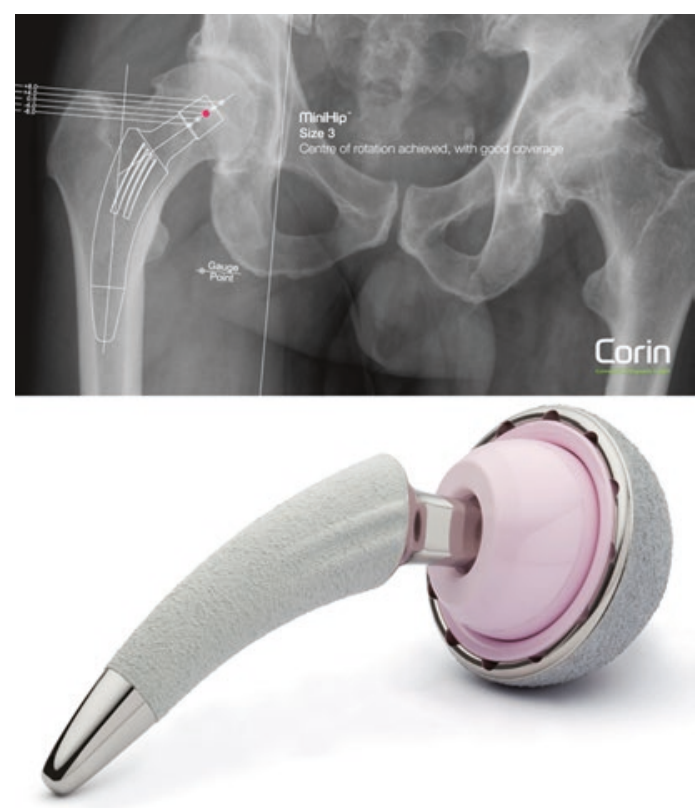

Fig. 3.4 A short femoral stem which loads only proximal bone by fixation in the femoral neck and metaphysis

ibility for positioning components, restoring constitutional hip biomechanics and impingement-free range of motion, and thus improving patient outcomes. Computer navigation systems, patient-specific instrumentation (Fig. 3.5), and robotics have been successively introduced with this goal in mind $[1,6]$. Patient-specific instrumentation (PSI) requires preoperative 3D imaging and computer-aided design (CAD) planning to create patient-specific cutting guides so that the surgeon can precisely size and position components to the preoperative plan. In contrast, computer navigation systems and robotics assist implantation through intraoperative 3D planning and then either guiding the position of the cutting blocks (computer navigation) or performing the cut (robotics). Slight displacement of the cutting blocks can occur when they are fixed to the bone with pins or during the bone cut by the saw. Robotics are thus considered to be more precise than computer navigation systems as they typically do not use cutting blocks; instead, power to the saw, reamer, or burr is terminated when placed in an orientation or position outside of the surgical plan. While 
Fig. 3.5 Patient-specific instrumentation - this cutting guide is $3 \mathrm{D}$ printed to match the patient's anatomy and deliver a planned cup orientation and femoral neck osteotomy

there is little doubt that these technologies improve surgical precision, their clinical benefit is yet to be proven compared to manual techniques for implanting components [6].

\subsection{Evolution of Hip Approaches}

The hip may be accessed through multiple anatomical routes to perform arthroplasty, typically via posterior, lateral, superior, or anterior surgical approaches. Access, by definition, disrupts the integrity of periarticular soft tissues, which in turn slows recovery after joint replacement and may sometimes be directly responsible for complications (e.g., instability, residual limp, pain, and heterotopic ossification). Minimally invasive surgical approaches such as the mini-posterior or the muscle-sparing approaches (including the Direct Anterior, Rottinger, SupraPath) were developed to reduce these issues (Fig. 3.6) [1, 17]. Their execution has been facilitated by the development of specific instrumentation and short femoral stem designs [16]. Compared to traditional approaches, minimally invasive surgical
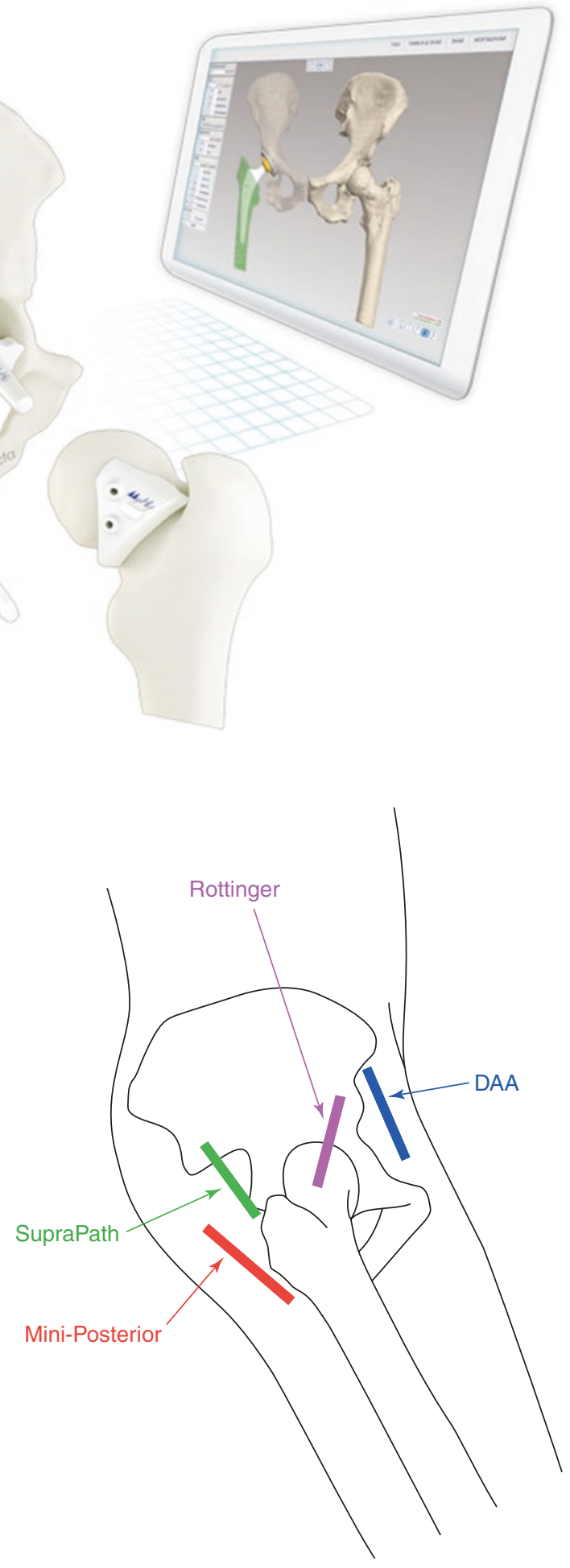

Fig. 3.6 Common minimally invasive surgical approaches to perform a hip replacement. DAA Direct anterior approach 
approaches have shown to be more technically demanding with subsequent longer learning curves, but can speedup recovery while keeping the dislocation rate similarly low $[6,17,18]$.

\subsection{Evolution of Techniques for Aligning Hip Components}

The 'mechanical alignment' technique (Fig. 3.7), defined half a century ago, is considered to be the gold standard technique for implanting total hip components $[19,20]$. It focuses on achieving a set biomechanical goal, while disregarding individual patient anatomy $[19,21]$. The hip's center of rotation is medialized to reduce stress on implants, and components are systematically oriented in universal "safe zones." The goal is to obtain a $15^{\circ}$ and $40^{\circ}$ radiographic cup anteversion and inclination, respectively, and to position the femoral stem with a $10^{\circ}$ to $15^{\circ}$ anteversion relative to the posterior condylar line [19-21]. Technological assistance has increased the reproducibility in positioning the cup, by defining the anterior pelvic plane and considering its tilt in either the supine or the standing positions; in this way, the concept of functional cup positioning was born [20, 22, 23].

Alternative concepts of combined anteversion [20, 24] and anatomical implantation [25-30] have gained relevance since the increased uptake of cementless femoral component. Cementless stems must obtain a stable press fit to obtain bone fixation, and thus adapt to the highly variable proximal femoral canal geometry. Therefore, unlike during implantation of cemented stems, there is limited ability to adjust femoral anteversion, and a greater risk of prosthetic impingement if the cup is systematically placed [7, 8, 31-33]. An increased awareness of this dynamic interplay between the acetabular and femoral components

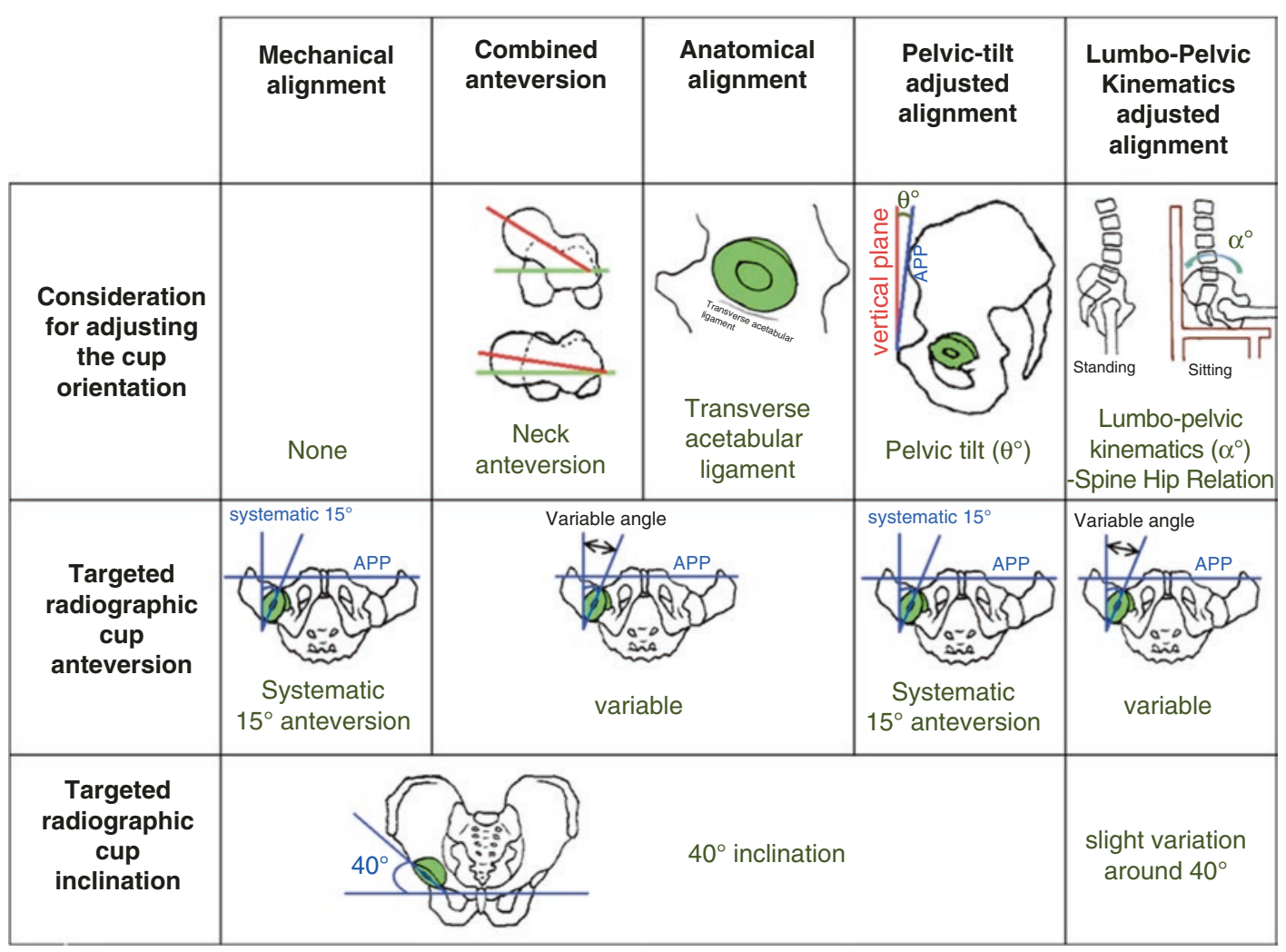

Fig. 3.7 This Figure illustrates the multiple techniques for aligning the acetabular component. APP Anterior pelvic plane 
$[34,35]$ led to the development of the combined anteversion technique [24]: the femur is prepared first - with the final rasp left in place while preparing the acetabulum. The chosen cup anteversion angle depends on the observed stem anteversion, and the resulting combined anteversion is typically between $30^{\circ}$ and $40^{\circ}$.

In contrast, the concept of anatomic implantation [25-30] of hip prostheses aims to restore the native hip anatomy with a focus on anatomical cup anteversion and restoration of hip center of rotation. The main rationale for an anatomical cup positioning is the limited ability to calculate an ideal cup orientation from preoperative images due to the multiple acetabular functional orientations and femoro-acetabular interplay combinations that an individual displays during ADLs [36-38]. It relies on intraoperative parameters such as the transverse acetabular ligament [25] and the use of calipers to precisely measure offset and neck length to define center of rotation. Anatomic implantation aims to restore native hip anatomy and improve prosthetic hip function and patient satisfaction by achieving physiological periprosthetic soft tissue balance and hip kinematics [29, 39]. The use of the neck-preserving femoral components (including resurfacing [27] or neck-sparing stem designs [16, 28]) facilitates anatomical restoration.

\subsection{Residual Complications with Conventional Implantation}

Although hip arthroplasty is considered a very successful procedure, and named the "operation of the century," there remain some residual complications [7, 31-33, 38]. Component loosening, late periprosthetic fracture, instability $(0-10 \%)[6,7]$, and residual pain in the absence of obvious complication (in 10-20\%) [31] are reported, suggesting that there is still room for significant improvement in implant design, techniques, and implementation of technology. Failures leading to revision surgery remain excessive and vary from $3 \%$ to $8 \%$ at 14 years postoperatively $[6,7]$. The main indications for revision surgery are aseptic loosening (48\% of revisions), followed by dislocation (15\%), periprosthetic fracture (10\%), and then sepsis (9\%) $[6,7]$. The risk and indication for revision surgery dramatically vary with patient age at the time of primary surgery, with younger patients more likely to require revision surgery $[6,7]$. Men implanted in their early 50s have a $30 \%$ lifetime revision risk compared to approximately $20 \%$ and $10 \%$ if the same primary replacement had occurred in their early 60 s or 70s, respectively [7]. Many of these residual complications have been primarily related to poor component interaction, i.e., to the frequent occurrence of edge loading [33] and prosthetic impingement $[32,38,39]$. These may be mitigated by the use of more forgiving (tolerant to edge loading and prosthetic impingement) implants and/or more personalized surgical techniques for implanting hip components.

\subsection{A Personalized Implantation May be the Next Step for Improvement of Clinical Outcomes}

The risks of prosthetic edge loading, prosthetic impingement, dislocation, and suboptimal prosthetic hip function have been shown to be significantly influenced by the condition of the lumbar spine (individual spine-hip relationship) [14, 40-43]. In contrast, those risks remain poorly predicted by the radiographic orientation of conventionally aligned cup $[10,12,14,32,35,44$, 45]. Despite our ability to precisely position implants using PSI, navigation, and robotic technology, there is limited evidence that they reduce dislocation or improve impingement-free range of motion $[6,46]$. This may be a consequence of a consistent standard (excessively systematic) technique of implantation, with insufficient attention paid to the many unique aspects that characterize each patient including their hip anatomy and kinematics. The truly "safe" acetabular target for avoiding impingement and edge loading is much smaller than previously understood and varies considerably between 
patients $[36,37,47,48]$, thus supporting a personalized philosophy for the choice of implant and placement of the components.

To improve clinical outcomes of hip replacement for the next century, we advocate for a more personalized implantation that considers lumbar spine kinematics/spine-hip relationship [49-52] and hip constitutional anatomy $[19,51,52]$ for a physiological and biomechanically sound hip arthroplasty. Surgical approach, implant design, and orientation should be dependent on a patient's unique anatomical and kinematic characteristics, and technological assistance can then be harnessed to precisely execute this patient-specific plan. By generating a physiological prosthetic hip (from anatomical restoration of the native) and by optimizing the components interaction during activities of daily living (from selecting a cup orientation that fits the spine flexibility), the kinematic alignment technique for hip replacement may perfect clinical outcomes of prosthetic hip. Precise kinematic alignment of forgiving, hard-wearing modern hip components may reach the ultimate goal of hip arthroplasty, which is generating a reproducible, durable, 'forgotten' prosthetic hip, and probably represents the future of hip arthroplasty.

\section{References}

1. Learmonth ID, Young C, Rorabeck C. The operation of the century: total hip replacement. Lancet. 2007;370(9597):1508-19.

2. Scheerlinck T, Casteleyn P-P. The design features of cemented femoral hip implants. J Bone Joint Surg Br. 2006;88-B(11):1409-18.

3. Langlais F, Kerboull M, Sedel L, Ling RSM. The 'French paradox'. J Bone Joint Surg Br. 2003;85-B(1):17-20.

4. Rivière C, Grappiolo G, Engh CA, Vidalain J-P, Chen A-F, Boehler N, et al. Long-term bone remodelling around 'legendary' cementless femoral stems. EFORT Open Rev. 2018;3(2):45-57.

5. Jaffe W, Scott D. Rationale and clinical application of hydroxyapatite coatings in pressfit total hip arthroplasty. Semin Arthroplast. 1993;4(3):159-66.

6. Ferguson RJ, Palmer AJ, Taylor A, Porter ML, Malchau H, Glyn-Jones S. Hip replacement. Lancet. 2018;392(10158):1662-71.

7. Commitee NS. National Joint Registry for England, Wales, Northern Ireland and the Isle of Man: 15th annual report, 2017. National Joint Registry Centre. 2018.

8. McCarthy TF, Nevelos J, Elmallah RK, Chughtai M, Khlopas A, Alipit V, et al. The effect of pelvic tilt and femoral head size on hip range-of-motion to impingement. J Arthroplast. 2017;32(11):3544-9.

9. Ezquerra L, Quilez MP, Pérez MÁ, Albareda J, Seral B. Range of movement for impingement and dislocation avoidance in total hip replacement predicted by finite element model. J Med Biol Eng. 2017;37(1):26-34.

10. Blakeney WG, Beaulieu Y, Puliero B, Lavigne M, Roy A, Massé V, et al. Excellent results of large-diameter ceramic-on-ceramic bearings in total hip arthroplasty. Bone Joint J. 2018;100(11):8.

11. McDonnell SM, Boyce G, Baré J, Young D, Shimmin AJ. The incidence of noise generation arising from the large-diameter Delta motion ceramic total hip bearing. Bone Jt J. 2013;95-B(2):160-5.

12. Tai SM, Munir S, Walter WL, Pearce SJ, Walter WK, Zicat BA. Squeaking in large diameter ceramicon-ceramic bearings in total hip arthroplasty. J Arthroplast. 2015;30(2):282-5.

13. Heffernan C, Banerjee S, Nevelos J, Macintyre J, Issa $\mathrm{K}$, Markel DC, et al. Does dual-mobility cup geometry affect posterior horizontal dislocation distance? Clin Orthop Relat Res. 2014;472(5):1535-44.

14. Dagneaux L, Marouby S, Maillot C, Canovas F, Rivière C. Dual mobility device reduces the risk of prosthetic hip instability for patients with degenerated spine: A case-control study. Orthop Traumatol Surg Res. 2019;105(3):461-6.

15. Darrith B, Courtney PM, Della Valle CJ. Outcomes of dual mobility components in total hip arthroplasty: a systematic review of the literature. Bone $\mathrm{Jt} \mathrm{J}$. 2018;100-B(1):11-9.

16. Khanuja HS, Banerjee S, Jain D, Pivec R, Mont MA. Short bone-conserving stems in cementless hip arthroplasty. J Bone Jt Surg Am. 2014;96(20):1742-52.

17. Mogliorini F, Biagini M, Rath B. Total hip arthroplasty: minimally invasive surgery or not? Meta-analysis of clinical trials. Int Orthop. 2018;43(7):1573-82.

18. Connolly KP, Kamath AF. Direct anterior total hip arthroplasty: comparative outcomes and contemporary results. World J Orthop. 2016;7(2):94.

19. Rivière C, Lazic S, Villet L, Wiart Y, Allwood SM, Cobb J. Kinematic alignment technique for total hip and knee arthroplasty: the personalized implant positioning surgery. EFORT Open Rev. 2018;3(3):98-105.

20. Bhaskar D, Rajpura A, Board T. Current concepts in acetabular positioning in total hip arthroplasty. Indian J Orthop. 2017;51(4):386.

21. Lazennec JY, Thauront F, Robbins CB, Pour AE. Acetabular and femoral anteversions in standing position are outside the proposed safe zone after total hip arthroplasty. J Arthroplast. 2017;32(11):3550-6.

22. Meftah M, Yadav A, Wong AC, Ranawat AS, Ranawat CS. A novel method for accurate and reproducible functional cup positioning in total hip arthroplasty. $\mathrm{J}$ Arthroplast. 2013;28(7):1200-5. 
23. Maratt JD, Esposito CI, McLawhorn AS, Jerabek SA, Padgett DE, Mayman DJ. Pelvic tilt in patients undergoing total hip arthroplasty: when does it matter? J Arthroplast. 2015;30(3):387-91.

24. Dorr LD, Malik A, Dastane M, Wan Z. Combined anteversion technique for total hip arthroplasty. Clin Orthop Relat Res. 2009;467(1):119-27.

25. Archbold HAP, Mohammed M, O'Brien S, Molloy D, McCONWAY J, Beverland DE. Limb length restoration during total hip arthroplasty: use of a caliper to control femoral component insertion and accurate acetabular placement relative to the transverse acetabular ligament. Hip Int. 2006;16(1):33-8.

26. Hill JC, Archbold HAP, Diamond OJ, Orr JF, Jaramaz $\mathrm{B}$, Beverland DE. Using a calliper to restore the Centre of the femoral head during total hip replacement. J Bone Joint Surg Br. 2012;94-B(11):1468-74.

27. Girard J, Lons A, Ramdane N, Putman S. Hip resurfacing before 50 years of age: a prospective study of 979 hips with a mean follow-up of 5.1 years. Orthop Traumatol Surg Res. 2018;104(3):295-9.

28. Shin Y-S, Suh D-H, Park J-H, Kim J-L, Han S-B. Comparison of specific femoral short stems and conventional-length stems in primary cementless total hip arthroplasty. Orthopedics. 2016;39(2):e311-7.

29. Patel AB, Wagle RR, Usrey MM, Thompson MT, Incavo SJ, Noble PC. Guidelines for implant placement to minimize impingement during activities of daily living after total hip arthroplasty. J Arthroplast. 2010;25(8):1275-1281.e1.

30. Meermans G, Van Doorn WJ, Koenraadt K, Kats J. The use of the transverse acetabular ligament for determining the orientation of the components in total hip replacement: a randomised controlled trial. Bone Jt J. 2014;96-B(3):312-8.

31. Beswick AD, Wylde V, Gooberman-Hill R, Blom A, Dieppe P. What proportion of patients report long-term pain after total hip or knee replacement for osteoarthritis? A systematic review of prospective studies in unselected patients. BMJ Open. 2012;2(1):e000435.

32. Marchetti E, Krantz N, Berton C, Bocquet D, Fouilleron N, Migaud H, et al. Component impingement in total hip arthroplasty: frequency and risk factors. A continuous retrieval analysis series of 416 cup. Orthop Traumatol Surg Res. 2011;97(2):127-33.

33. Hua X, Li J, Jin Z, Fisher J. The contact mechanics and occurrence of edge loading in modular metalon-polyethylene total hip replacement during daily activities. Med Eng Phys. 2016;38(6):518-25.

34. Rivière C, Lazennec J-Y, Van Der Straeten C, Auvinet E, Cobb J, Muirhead-Allwood S. The influence of spine-hip relations on total hip replacement: a systematic review. Orthop Traumatol Surg Res. 2017;103(4):559-68.

35. Mayeda BF, Haw JG, Battenberg AK, Schmalzried TP. Femoral-acetabular mating: the effect of femoral and combined anteversion on cross-linked polyethylene wear. J Arthroplast. 2018;33(10):3320-4.

36. Nam D, Riegler V, Clohisy JC, Nunley RM, Barrack RL. The impact of total hip arthroplasty on pelvic motion and functional component position is highly variable. J Arthroplast. 2017;32(4):1200-5.

37. Mellon SJ, Grammatopoulos G, Andersen MS, Pandit HG, Gill HS, Murray DW. Optimal acetabular component orientation estimated using edge-loading and impingement risk in patients with metal-onmetal hip resurfacing arthroplasty. J Biomech. 2015;48(2):318-23.

38. McCarthy TF, Alipit V, Nevelos J, Elmallah RK, Mont MA. Acetabular cup anteversion and inclination in hip range of motion to impingement. J Arthroplast. 2016;31(9):264-8.

39. Shoji T, Yamasaki T, Izumi S, Kenji M, Sawa M, Yasunaga Y, et al. The effect of cup medialization and lateralization on hip range of motion in total hip arthroplasty. Clin Biomech. 2018;57:121-8.

40. Pierrepont JW, Feyen H, Miles BP, Young DA, Baré JV, Shimmin AJ. Functional orientation of the acetabular component in ceramic-on-ceramic total hip arthroplasty and its relevance to squeaking. Bone Jt J. 2016;98-B(7):910-6.

41. Heckmann N, McKnight B, Stefl M, Trasolini NA, Ike H, Dorr LD. Late dislocation following total hip arthroplasty: spinopelvic imbalance as a causative factor. J Bone Jt Surg. 2018;100(21):1845-53.

42. Grammatopoulos G, Dhaliwal K, Pradhan R, Parker SJM, Lynch K, Marshall R. Does lumbar arthrodesis compromise outcome of total hip arthroplasty? Hip Int. 2019;29(5):496-503.

43. Ochi H, Homma Y, Baba T, Nojiri H, Matsumoto M, Kaneko K. Sagittal spinopelvic alignment predicts hip function after total hip arthroplasty. Gait Posture. 2017;52:293-300.

44. Abdel MP, von Roth P, Jennings MT, Hanssen AD, Pagnano MW. What safe zone? The vast majority of dislocated THAs are within the Lewinnek safe zone for acetabular component position. Clin Orthop Relat Res. 2016;474(2):386-91.

45. Goyal P, Lau A, Naudie DD, Teeter MG, Lanting BA, Howard JL. Effect of acetabular component positioning on functional outcomes in primary total hip arthroplasty. J Arthroplast. 2017;32(3): 843-8.

46. Reininga IH, Zijlstra W, Wagenmakers R, Boerboom AL, Huijbers BP, Groothoff JW, et al. Minimally invasive and computer-navigated total hip arthroplasty: a qualitative and systematic review of the literature. BMC Musculoskelet Disord. 2010;11(1):92. http://bmcmusculoskeletdisord.biomedcentral.com/ articles/10.1186/1471-2474-11-92

47. McCarthy TF, Alipit V, Nevelos J, Elmallah RK, Mont MA. Acetabular cup anteversion and inclination in hip range of motion to impingement. $\mathrm{J}$ arthroplast. 2016;31(9):264-8.

48. Pierrepont J, Hawdon G, Miles BP, Connor BO, Baré $\mathrm{J}$, Walter LR, et al. Variation in functional pelvic tilt in patients undergoing total hip arthroplasty. Bone Jt J. 2017;99-B(2):184-91.

49. Stefl M, Lundergan W, Heckmann N, McKnight B, Ike $\mathrm{H}$, Murgai R, et al. Spinopelvic mobility and 
acetabular component position for total hip arthroplasty. Bone Jt J. 2017;99-B(1_Supple_A):37-45.

50. Phan D, Bederman SS, Schwarzkopf R. The influence of sagittal spinal deformity on anteversion of the acetabular component in total hip arthroplasty. Bone Jt J. 2015;97-B(8):1017-23.

51. Riviere C. Kinematic versus conventional alignment techniques for total hip arthroplasty: a retrospective case control study. Orthop Traumatol Surg Res. 2019;105(5):895-905.

52. Spencer-Gardner L, Pierrepont J, Topham M, Baré J, McMahon S, Shimmin AJ. Patient-specific instrumentation improves the accuracy of acetabular component placement in total hip arthroplasty. Bone Jt J. 2016;98-B(10):1342-6.

Open Access This chapter is licensed under the terms of the Creative Commons Attribution 4.0 International License (http://creativecommons.org/licenses/by/4.0/), which permits use, sharing, adaptation, distribution and reproduction in any medium or format, as long as you give appropriate credit to the original author(s) and the source, provide a link to the Creative Commons license and indicate if changes were made.

The images or other third party material in this chapter are included in the chapter's Creative Commons license, unless indicated otherwise in a credit line to the material. If material is not included in the chapter's Creative Commons license and your intended use is not permitted by statutory regulation or exceeds the permitted use, you will need to obtain permission directly from the copyright holder. 